\title{
VACUIDAD Y ESTULTICIA: TRASTORNO ESPIRITUAL
}

\author{
EMPTINESS AND FOOLISHNESS: SPIRITUAL DISORDER \\ Martín Nizama V. ${ }^{1}$ \\ Instituto Nacional de Salud Mental Honorio Delgado-Hideyo Noguchi, Perú \\ (RECIBIDO EL 25/02/2010, ACEPTADO EL 15/06/2010)
}

\begin{abstract}
RESUMEN
Se efectúa una reflexión humanista sobre la espiritualidad en la posmodernidad, cuya sociedad del conocimiento muestra como contraparte la vacuidad de la cual se evaden masivamente las personas hacia la materialidad, la estulticia, la insensibilidad, el hedonismo y la violencia, lo cual configura una sociedad decadente y deshumanizada, en cuyo trasfondo subyace el desamor familiar, la pérdida de los valores y la prelación de los antivalores en el ethos social y los estilos de vida. El modelo de familia natural, fuente de amor, se encuentra en extinción y es sustituida aceleradamente por el modelo de familia moderna, liberal y asistencialista con pérdida del rol de los padres, quienes han abdicado de su autoridad, de su rol protector y formativo en favor del rol de padres proveedores. Se define el concepto de vacuidad, sus causas probables, su fenomenología y se describe el ethos social de la fatuidad. Seguidamente, se aborda la estulticia y las consecuencias sociales de la vacuidad y de la estulticia; se propone un afronte holístico y aspectos preventivo promocionales, efectuándose un análisis y formulándose algunas conclusiones. Finalmente, se presentan viñetas de 17 casos de la actual generación vacua.
\end{abstract}

Palabras clave: Deshumanización; vacuidad; estulticia.

\begin{abstract}
It is realized a humanistic reflection about spirituality in the post modernity, whose knowledgement society shows as antonymous the emptiness, from what people escapes largely to materiality, the stupidity, foolishness , insensibility, hedonism and violence; that configure a decadent deshumanized society, in whose base underlie familiar unlove, lack of human value and antivalues anticipation in social ethos and lifestyles. The natural family model, source of love, is in extinction and is quickly exchanged by a modern, liberal and asistencialist family model, with lack of parents rol, who have lost their authority, protector and formative rol by the providing parents role. It is defined the concept of emptiness, its probably causes, its phenomenology and the fatuity social ethos is described. After that, foolishness and the social consequences of emptiness and foolishness, it is proposed an holistic focus and preventive and promotional aspects, realizing analyze and formuling some

1 Médico psiquiatra, experto en adicciones, doctor en Medicina, profesor principal de los Departamentos Académicos de Psiquiatría de la Universidad Nacional Mayor de San Marcos y de la Universidad Peruana Cayetano Heredia, ex director general de concursado del Instituto Nacional de Salud Mental "Honorio Delgado - Hideyo Noguchi".

E-mail: maniva@terra.com.pe.
\end{abstract}


conclusions. Finally, there are seventeen examples of the empty generation.

Keywords: Deshumanization; emptiness; foolishness.

\section{INTRODUCCIÓN}

En la sociedad del conocimiento y de las megatendencias de la posmodernidad crece aceleradamente el vacío espiritual en los seres humanos; principalmente en los grupos etarios de la niñez, adolescencia y juventud de la sociedad global; la misma que se encuentra saturada de hedonismo, materialidad, sensualidad, fatuidad, aburrimiento (Russell, 2003), infelicidad y evasión hacia el fanatismo, el desenfreno, la irracionalidad y las experiencias de vida extremas - a menudo con efectos devastadores, autodestructivos y heterodestructivos (Nizama, 2003) - , sin una cabal conciencia de ello en el individuo, la familia, la colectividad, ni en las autoridades de salud mental, nacionales e internacionales. Pareciera que el modelo de vida de la actual sociedad global se estuviera agotando y dando paso a una sociedad decadente, de cuyo seno seguramente ha de surgir la aurora de un nuevo tipo de sociedad más sensible, más humana. Son las oscilaciones pendulares de la historia de la civilización.

La vacuidad es una manifestación de la deshumanización social masiva que se origina en la célula familiar y es retroalimentada por la sociedad materialista, consumista y no ética en la cual vivimos. Este vacío espiritual multicausal es generado, principalmente, por la ausencia de amor en la familia, razón por la cual la persona no aprende principios, valores, sentimientos superiores, ni la moral que deberían inculcarle los paradigmas paternos, naturales o sustitutos, en el seno del hogar y complementar las instituciones educativas, laborales y sociales. En la familia moderna prevalece el desamor familiar (Nizama, 2009). Los estilos de vida actual están signados por la fatuidad, el hedonismo y, a menudo, por el desenfreno sensual.

Paralelamente prevalece una cultura de retórica espuria que predica lo contrario de lo que se practica en la vida cotidiana. Así, es común observar que políticos, gobernantes, autoridades, clérigos, líderes sociales y personalidades públicas se engolan pontificando de manera ostentosa sobre la moral, los valores, principios e ideales, cuando en los hechos concretos imperan los antivalores y toda suerte de modelos fatuos, propiciados ex profeso; puesto que el ser humano masificado necesita llenar sus vacíos espirituales con lo que encuentre, de la manera más fácil y expeditiva posible, sea televisión cloacal, estridencia musical, mediante la concupiscencia o la actuación escénica. Por ejemplo, los reality shows se han convertido en un fenómeno mediático en la sociedad global y local que prodiga elevados ratings a los programas que propalan la vida personal, hedonista, intimidades, chismes y escándalos de los personajes del espectáculo (farándula), que de esta manera son convertidos en un producto de consumo masivo en todos los estratos sociales, llenando los vacíos espirituales de la gente urgida de banalidad.

Los realitys en un principio se centraban en figuras mediáticas. Sin embargo, actualmente gran parte de estos programas incluyen como personajes centrales a gente común, frívola o intrascendente, dispuesta a actuar todo lo que se les proponga solo por el afán de figuretismo y dinero (más por notoriedad que por dinero), lo cual indica una búsqueda 
ansiosa de aceptación social e incluso, más allá, búsqueda de reconocimiento, aunque no por algo relevante, sino simplemente por la necesidad de hacerse popular de la manera más fácil y estrambótica.

No obstante, la vacuidad puede estar asociada al éxito fácil en determinados escenarios sociales light, lo cual comúnmente es valorado como normal en estratos sociales necesitados de íconos fatuos, a los cuales suele sacralizar; puesto que el ser humano necesita admirar, pertenecer e identificarse con todo aquello que le genere seguridad, placer y emoción. Al respecto, Rainer Funk, en su introducción al libro La vida auténtica de Erich Fromm, formuló el concepto de "realidad fabricada, creada, producida...", en el cual se gesta el "yo escenificado”, Fromm, en este su libro, se pregunta: “¿cómo se debe encauzar la vida? ¿Hacia dónde hay que ir? ¿Qué sentido tiene la existencia?” (Fromm, 2007), con lo cual plantea el misterio de por qué existimos.

\section{DENOMINACIÓN SOCIAL}

En el lenguaje común este fenómeno de alienación psicosocial es denominado así: "cabeza hueca”, "calabaza”, "tonel vacío", "estar en nada”.

\section{DEFINICIÓN}

La vacuidad es la carencia de contenido espiritual en la persona; un foso profundo en la interioridad humana. La orfandad de amor a sí mismo e incapacidad de amar al prójimo sumerge a la persona en una inmensa soledad, sensación de inexistencia interior, en el sin sentido de la existencia y ausencia de un proyecto de realización personal; al igual que en la egolatría, infelicidad y permanente actitud evasiva, en una búsqueda insaciable de felicidad artificial.

\section{CAUSAS}

Las causas de este trastorno de la esencia humana aún son insuficientemente conocidas; no obstante sus probables causas serían:

- Desamor familiar.

- Decadencia de la institución familiar.

- Paternidad asistencialista.

- Ausencia de paradigmas auténticos.

- Íconos fatuos.

- Entronización de la vida materialista.

FENOMENOLOGÍA 
La vacuidad se caracteriza por la sensación de inexistencia interior, soledad, hastío, carencia de voluntad de sentido (Frankl, 1994, 2000 y 2003), de sentido de existencia (Frankl 2001, 2003) y de proyecto de vida, asociado a la soberbia compensatoria de la baja autoestima. Así, desorientada y desubicada la persona, agobiada por la angustia intensa que le acarrea el hastío, evade de manera compulsiva su realidad, refugiándose en el hedonismo, la sensualidad, fatuidad, estulticia, el desenfreno irracional o en el mundo virtual. No vive su realidad, imita los prototipos que le impone la publicidad mediática. También asume los estereotipos de las culturas y sociedades foráneas o impuestos por entornos caracterizados por la alienación psicosocial. Puede llevar una doble vida. Entonces desprecia lo propio y se aferra de manera pática e irracional a lo exógeno. Así, pierde su identidad esencial, se torna insensible, hostil o distante de su familia a la cual solo se acerca para utilizarla, maltratarla, manipularla o chantajearla en procura de sus fines ególatras, oportunistas o por codicia.

El humano deja de ser lo que es, un ser esencial, para convertirse en un ser sensual que vive exclusivamente el principio hedonista: entregado a los placeres del momento y nada más, adicto a la concupiscencia. La persona carece de conciencia de este trastorno espiritual, y por el contrario se valora como superior a los demás a los cuales desdeña o subestima, mofándose de ellos, a menudo de manera acre. Se torna insensible y a menudo robotizado, manipulado por el escenario de su entorno al cual se adhiere incondicionalmente. Entonces actúa en función de su escenario de pertenencia, perdiendo su esencia humana, su sí mismo.

\section{ETHOS SOCIAL}

La persona frívola evidencia su alienación psicosocial de diversas maneras: sacralización del individualismo, estulticia, excentricidad, fariseísmo y estilos de vida sensuales, por ejemplo un grupo emo, punk, metrosexual. Así mismo, tiene una doble vida, una formal con su familia, otra fatua y velada con su entorno amical y social. Igualmente, muestraa fanatismo por la música a volumen estridente, lo cual constituye una forma de aislamiento. Otras veces puede desarrollar promiscuidad sexual. Luce modas estrafalarias, peinados extravagantes, piercing y tatuaje corporal. Vive de modo acelerado el momento y nada más, cautivo de la inmediatez. Quema etapas de su vida. Siendo aún adolescente o joven lleva una vida de adulto ("agrandada") y se apasiona por divertirse con personas mayores de edad o con más recorrido social. Vive el sin sentido de vida y exige libertad irrestricta (libertinaje). Sus expresiones predilectas suelen ser: "déjenme ser"; "vive la vida antes que la vida te viva"; "me aburro de estar aburrido". Todo ello con carácter prioritario, urgente y excluyente. Su leitmotiv es: "vivir el vacilón al toque, al máximo, sin frenos, fácil y con adrenalina” (riesgo).

Algunos millonarios y famosos playboys, personajes del jet set internacional, así como publicitados artistas, modelos y deportistas, se han convertido en paradigmas del consumismo para las generaciones juveniles debido a su vida escandalosa y excéntrica, caracterizada por el derroche de dinero en cantidades fastuosas y de glamour que cotidianamente propalan con estridencia en los medios de comunicación, lo que de esta manera orienta a la sociedad en dirección de la vida fatua cuya expresión emblemática 
es Hollywood, capital mundial de la vacuidad, banalidad y estulticia. Por ejemplo, la modelo y actriz estadounidense, Paris Hilton (26 años), multimillonaria heredera de la cadena de hoteles Hilton, en una oportunidad declaró a la prensa: "una de mis heroínas es Barbie. Puede que no haga nada, pero siempre luce regia haciéndolo". Fue condenada a pasar 45 días en la cárcel por conducir sin licencia, ebria y por ser reincidente. Luego de haber cumplido solo 23 días de prisión fue liberada, y en una entrevista televisiva (CNN) que concedió al periodista Larry King, ella manifestó que su encierro carcelario le había cambiado la vida. También refirió a King que en su época escolar en el colegio religioso donde estudió había leído la Biblia. Preguntada por King sobre qué pasaje de la Biblia le había agradado más, ella respondió que no recordaba. Ulteriormente, su abuelo Barron Hilton agobiado por la vida escandalosa y desenfrenada que llevaba en fiestas, así como sus videos sexuales, el consumo de drogas y la carcelería de su nieta, la borró de su testamento, lo cual le representó a la diva la pérdida de unos 60 millones de dólares.

Y respecto al futbolista inglés, aunque más modelo publicitario que deportista, David Beckham, el escritor uruguayo Eduardo Galeano comentó: "confundo al jugador con el producto. Es bueno, aunque me da alergia. Da la sensación de ser algo de consumo obligatorio. O lo compras o lo dejas". Por su lado, la actriz británica Emma Watson, quien da vida a Hermione en la saga de Harry Potter, manifestó que nunca pensó en ser actriz y que ahora no sabe qué hará con su fortuna, estimada en más de 20 millones de dólares. Seguidamente acotó: “¿¡Para qué alguien de mi edad necesitaría tanto dinero!? Seamos sinceros, realmente no tengo en qué gastarlo". Estos son solo algunos signos de la riqueza extrema que se da en las minúsculas élites de la pirámide social del mundo, en contraste con la pobreza extrema que sufren millones de seres humanos, crónicamente privados de oportunidades de subsistencia digna. ¿Y, los principios de equidad, igualdad y justicia?

Habitualmente, la persona vacía subestima lo convencional y a las personas mayores, a quienes moteja con adjetivos despectivos o de sorna. Valora como insulsos los estudios, la actividad laboral y el comportamiento social formal, satirizándolo y haciendo escarnio de lo auténtico. Evade la profundidad espiritual, lo sustancial y trascendente. Se autoendiosa envuelta en el halo de lo trivial e intrascendente. Así, oye pero no escucha. Es vidente para afuera y ciega para adentro. De este modo, vive todo para afuera y nada para adentro. Su comportamiento está hegemonizado por la estulticia y la mera apariencia: actuación teatral.

\section{ESTULTICIA}

La estulticia es el refugio de la vacuidad. Por ello, el estulto realiza infinidad de actividades necias y fatuas que él valora como esenciales. Con fanatismo, desenfreno, apego desmedido o irracionalidad, desarrolla una serie de actividades banales a las cuales convierte en estilos de vida esnob personales. Así, consagra su vida a asistir a conciertos musicales, campamentos, discotecas, playas, gimnasio o competencia de carreras clandestinas de autos ("piques"). De modo excluyente, su círculo amical lo constituyen personajes estrafalarios o adictos a algo. Otras veces se refugia en el mundo hedonista y liviano de la farándula o de la vida nocturna fragorosa. Cuando no, se convierte en un cibernauta conectado como autómata ("pegado") al mundo virtual. Dedica la mayor parte de su tiempo a bajar 
pornografía; se amanece en el messenger, chateando; dispendia su tiempo en las redes sociales: flickr, twitter, Hi5, youtube, facebook, myspace, second life, skype, blogs, etc. También se consagra a los clubs de fans. Si no, a los casinos, máquinas tragamonedas, máquinas chinas, playstation, nintendo, X-box, juegos en red. O, a las "pijamadas" (dormir en casa de amigos), al juego con réplicas de armas bélicas (airsoft, paintball), a la televisión basura, telenovelas, pornografía en video, fiestas con luces, rituales místicos o esotéricos. Esta situación ha conducido a la denominada generación vacua o generación "Y" (homo videns), a la pérdida del hábito de la lectura, lo cual influye negativamente en el desarrollo cultural del individuo; puesto que la lectura prodiga inconmensurables beneficios tanto al lector como a la familia.

También, el estulto suele refugiarse en la ingesta de bebidas alcohólicas, en el uso de tabaco o comer en exceso y a cada momento ("picar"). Así mismo, en la automedicación con psicofármacos y analgésicos, con lo cual llena compulsivamente sus vacíos existenciales. Todo ello, lo practica con vehemencia e irresponsabilidad, además de aislarse de su familia o de mostrarse hostil y aun agresivo o violento con ella. Poseen una voracidad consumista.

Otras maneras de evadir la vacuidad son la adopción de la beatería monocorde como forma de vida; la entrega a la corrupción, lujuria, fastuosidad, adulación, ostentación, insensatez, escotosis ("ceguera" mental), abusos, gula, envidia, avaricia, ociosidad y mendacidad, entre otras actividades banales y disociales.

Sin embargo, los refugios con mayor compromiso patológico son la militancia en las barras bravas, pandillas juveniles, grupos de "pirañas" (delincuentes infantiles), bandas de asaltantes, adicciones, vagancia inveterada, doble vida, esclavitud espiritual en grupos rasta (naturalistas) o sectas de fanatismo religioso, entre otros descarrilamientos graves. $\mathrm{Su}$ vida gira alrededor de estos escapes frívolos, a los cuales se adhiere irracionalmente, sin posibilidad de salir por sí mismo de su agujero negro. A la par, detesta los estudios, a su familia y desatiende o desdeña su trabajo o su quehacer profesional. Carece del más elemental sentido de autocrítica. Finalmente acaba en la autodestrucción, sin conciencia de ello.

Sin embargo, debe diferenciar el uso del abuso y la adicción. Se entiende por uso, el empleo racional y beneficiario de algo; abuso, es la utilización desmedida de ese algo, y la adicción, es la dependencia de ese algo para sentirse bien, si se carece de ello causa malestar y para restablecer la sensación de bienestar, la persona necesita recuperar ese algo.

Cabe deslindar que no toda actividad recreativa; o que sea necesaria para el desempeño personal; para el quehacer cotidiano o doméstico, es perniciosa. La manifestación patológica la constituye el exceso, el descarrilamiento y las aberraciones, con daño a sí mismo y a los demás.

La palabra estulticia proviene del término latino stultitia, necedad o falta de inteligencia. Erasmo de Rotterdam utiliza este concepto para satirizar con mordacidad e ingenio las desviaciones de la iglesia católica de su tiempo en su obra titulada en griego, Morias Enkomion (Encomio de la Estulticia o Elogio de la Tontería), mal traducida al castellano como Elogio de la Locura (Rotterdam, 2004). 


\section{CONSECUENCIAS}

Entre las múltiples consecuencias de este trastorno espiritual se pueden citar las siguientes:

- Consumismo irracional.

- Deshumanización social masiva.

- $\quad$ Estilos de vida materialista.

- Hedonismo.

- Sensualidad.

- Mercantilismo mediático.

- Corrupción indiscriminada.

- Disrupción del tejido social.

\section{AFRONTE HOLÍSTICO}

El manejo de la vacuidad y la estulticia se sustenta en los tres principios de la logoterapia: 1) la vida tiene sentido en todas las circunstancias, 2) el ser humano es dueño de una voluntad de sentido y se siente frustrado o vacío cuando deja de ejercerla, y 3) la persona es libre dentro de sus obvias limitaciones, para consumar el sentido de su existencia (Luna, 1999). Para el efecto se propone el siguiente afronte holístico:

- Contrarrestar la cultura de la banalidad con lectura y arte.

- Cultivar el amor familiar sostenido.

- Practicar la comunicación familiar auténtica.

- $\quad$ Ejercer la paternidad responsable.

- Desarrollar la espiritualidad plena.

- Practicar estilos de vida saludables.

- Fomentar el hogar saludable.

- Desapego de la vida materialista.

\section{PREVENCIÓN}

Básicamente, la prevención del vacío espiritual y la estulticia es familiar, a saber:

- Detección precoz y manejo de los desajustes familiares.

- Supresión de la televisión basura en el hogar.

- Control temprano del ciberabuso. 
- Desarraigo de los círculos amicales sin valía espiritual.

- Supresión de la cultura escatológica (sucia) en el seno de la familia.

- Erradicación de los estilos de vida malsanos.

- Romper la incomunicación familiar.

\section{PROMOCIÓN}

Se propone desarrollar las siguientes acciones de promoción de la salud espiritual:

- Lectura educativa en base a obras clásicas y modernas, formativas.

- Cultivar las artes: música saludable, pintura, poesía, teatro, deporte.

- Desarrollar la escala axiológica.

- Practicar la meditación, reflexión y la autocrítica.

- Promover la sociedad ética.

- Ofertar paradigmas familiares y sociales adecuados.

- Promover el desarrollo del amor familiar.

- Fortalecer la institución familiar.

- Acceder al círculo virtuoso de amigos.

- Desarrollar la cultura de la felicidad.

La lectura es una prodigiosa fuente de conocimiento, desarrolla la actitud crítica, la imaginación, el análisis y la síntesis. Y, al proveer al individuo de estas habilidades, le brinda seguridad y confianza en sí mismo. Por otro lado, la lectura sirve como medio de integración familiar, promueve la discusión de ideas y opiniones. Se convierte así en un espacio de interacción familiar en el que se ejerce el respeto y la tolerancia a las formas de pensar diferentes a las de uno mismo. También permite a los padres conocer cómo los hijos perciben y evalúan la realidad.

El amor es el factor protector más poderoso contra toda forma de patología psíquica. La familia es la fuente natural del amor donde se le cultiva cotidianamente. Las expresiones de amor son la atención, compartir tiempo, las caricias, el reconocimiento, la comprensión, la comunicación auténtica, la solidaridad y el apoyo permanente. El amor no se compra con objetos, ni dinero; tampoco se exige, se mendiga, ni se impone.

Boris Cyrulnik (2005) afirma que "se necesita amor para que el niño se interese en el mundo, luego se necesita que el amor muera para que el niño se convierta en una persona, para educarlo, es decir llevarlo fuera de sí. Sin amor, las cosas no adquieren sentido. Pero cuando el amor no se apaga, la fusión crea un mundo siamés" (simbiótico). Este mismo autor acota que "cuando la madre muere, enferma o se deprime y la familia o la cultura no organizan un sustituto materno, el medio sensorial del niño se empobrece enormemente. 
La creación de los circuitos cerebrales cortos se hace más lenta. El empobrecimiento del medio, provocado por el sufrimiento de la madre o por la deficiencia cultural explica una parte de las atrofias frontolímbicas. Estos niños que se encuentran en la situación de carencia afectiva quedan privados de las estimulaciones biológicas iniciales" (Cyrulnik, 2007).

\section{GENERACIÓN VACUA}

Muchos jóvenes en la posmodernidad pertenecen a la generación vacua. Proceden de familias disfuncionales a cuyos padres, mayormente, solo les interesan los aspectos materiales y financieros: proveer de dinero a sus hijos en cantidades desmedidas para que ellos hagan su vida como mejor les parezca, de manera libérrima. Dichos padres no se preocupan por ser paradigmas positivos para sus hijos; por el contrario les apoyan sus malacrianzas, no los orientan, ni les corrigen sus defectos. Han abdicado de la paternidad responsable, desconocen que la educación comienza en el hogar; que ellos son los primeros modelos para la vida y el futuro de sus hijos. También ignoran que el hogar es la sede del nido familiar, manantial del amor.

Estos jóvenes cautivos de la vacuidad y la estulticia buscan infinidad de maneras de evadir su entorno familiar, en la creencia errónea de que la mejor opción de vida es sujetarse exclusivamente a los bienes materiales, al esnobismo, a la sensualidad y a lo último de la tecnología electrónica para gozar de la diversión, el entretenimiento y el full confort. Quien posee vacuidad cree expresar amor mediante relaciones meramente banales, sensuales o utilitaristas. Sin embargo, no es así porque desconoce su naturaleza humana y posee una percepción materialista de la vida.

Estos trastornos espirituales, la vacuidad y la estulticia, mayormente, son atribuibles a los padres que se enajenan emocionalmente de sus hijos, no los forman espiritualmente ni se interesan generalmente por su desarrollo humano integral. Comúnmente se limitan a endosar a sus hijos a terceras personas o a instituciones tutelares para que se encarguen de su crianza y satisfacción de necesidades, y suelen ser criados por la trabajadora del hogar, abuelos, otros familiares o en guarderías. Por este motivo, los padres comúnmente desconocen cómo se encuentran sus hijos espiritualmente.

La persona estulta sufre interiormente, pero no lo demuestra. Como humano que es necesita el amor que sus padres no le prodigaron. No basta con haber estudiado en los mejores centros educativos, lo primero es velar por su salud psíquica y bienestar. El joven necesita atención y aprender a sentir lo que es el amor auténtico y, lo más importante, el amor familiar y aprender a ser feliz.

\section{CONCLUSIONES}

La globalización tiene como bien la sociedad del conocimiento y como contraparte la vacuidad y la estulticia.

En la sociedad de la vacuidad y la estulticia prevalece la vida materialista y hedonista. 
La vida materialista y hedonista es el germen de una sociedad no ética y amoral.

La familia tradicional se encuentra en proceso de extinción y está siendo sustituida por la familia proveedora.

La insensibilidad social se masifica en la sociedad no ética.

El modelo de sociedad posmoderna ha generado una generación vacua, juvenil.

La deshumanización masiva conduce a una sociedad decadente.

Urge revertir la sociedad de los antivalores, rehumanizándola cuanto antes.

Hay inconciencia social sobre la decadencia de la sociedad humana.

Los líderes locales, nacionales y mundiales se muestran indolentes ante el fenómeno de la vacuidad y la estulticia.

\section{CASUÍSTICA}

A continuación se presentan algunas viñetas acerca de la vacuidad y la estulticia en la vida social cotidiana y que comúnmente pasan inadvertidas.

\section{Caso 1}

Karen es una adolescente de 14 años de edad, residente en San Isidro, estudiante del tercero de secundaria de un colegio A1 de Lima, quien acude a la consulta médica por presión de sus padres, quienes se encuentran divorciados y cada uno con una nueva pareja. El padre refiere: "mi hija tiene las pupilas dilatadas. Eso es por droga". Por su lado, la madre enfurecida acusa al padre de difamar y ofender a su hija: "tú no la conoces, no vives con ella", le vocifera en actitud desafiante y agresiva. En la entrevista personal, Karen manifiesta: "yo no sé por qué me traen", "odio a mi padre", "mis padres son unos aburridos". Tiene tres cursos reprobados en su tarjeta de notas. Le han puesto tres profesores para los cursos desaprobados, detesta asistir al colegio, rehúsa a que la transporten al colegio y que la recojan sus padres porque según ella se avergüenza. Solo desea estar en casa de sus amigas, en fiestas, pijamadas, campamentos y conciertos musicales. La entrevista personal y el examen toxicológico determinaron que no consumía drogas al momento de su evaluación. Vive el sin sentido de existencia, se muestra infatuada, abúlica y desmotivada para la entrevista a la cual ha asistido solo para complacer a sus padres. No demuestra ningún interés en su futuro personal, carece de ideales, sueños y de un proyecto de vida. La entrevista se efectuó en junio de 2007 en la consulta externa de una clínica privada de San Isidro.

\section{Caso 2}

Renzo es un adolescente varón de 14 años de edad, domiciliado en el distrito de Los Olivos (Lima Norte). Sus padres trabajan, él como taxista y ella como técnica administrativa en un centro de salud de Lima Norte. Desde los 10 años de edad Renzo comienza a cambiar progresivamente su comportamiento, se consagra al messenger, al cual dedica muchas horas hasta el punto de amanecerse 2 a 3 veces por semana, "sólo ahí me encuentro a gusto", refiere. Su comportamiento es estulto (necio), desobediente, intolerante y sobrevalorado 
("agrandado"). Igualmente muestra desinterés por el estudio; está irritable e irascible. Ante una pregunta de su madre: "hijo, ¿cuál es tu mayor ilusión?”, él le contestó: "que te largues de la casa para yo quedarme con mi papá". Siempre amenaza a su madre: "si haces eso o aquello me largo de tu maldita casa". Padre pusilánime, tiembla ante las amenazas de su hijo. Durante la entrevista personal, Renzo se mostró indiferente, desmotivado, calculador y negativista a colaborar con el médico en la entrevista. Se descartó consumo de drogas mediante el examen toxicológico.

\section{Caso 3}

Diana tiene 18 años de edad. Reside en el distrito de Ventanilla (Callao), es una adolescente que se siente completamente sola y vacía. Su madre siempre le infligió maltratos psíquicos; de niña no le dio la educación que debió prodigarle. Con profundo rencor manifiesta que su madre es la peor persona que hay en la tierra; que nunca le demostró afecto y solo se dedica a reprocharla diciéndole: "estás gorda y eres una burra". Confidenciaba a su mejor amiga que su madre la aburría y la tenía estresada, que deseaba fugarse del hogar. Con dicha amiga compartía todos sus secretos y sentimientos más íntimos. Hacía saber a su amiga que la quería mucho y que nunca la iba a traicionar. Finalmente no resultó ser así porque Diana acabó usurpándole el enamorado a su mejor amiga.

Desde los 15 años de edad empezó a mostrarse muy rebelde y se aislaba en su casa. $\mathrm{Su}$ progenitor, la única persona que le prodigaba cariño, era un padre ausente porque constantemente viajaba y no estaba en casa. Diana, a esa edad, tuvo un enamorado un año menor que ella. Sentía que él realmente la quería y comenzó a tener intimidad sexual con este adolescente. Diana contaba a sus amigas que veía pornografía con él; luego comenzó a realizar orgías con sus compañeros de colegio; abiertamente contaba a sus amigas todo lo que hacían. Como su madre no le daba permiso para salir; ella dejaba de asistir al colegio y se iba con su pareja a algún lugar donde, según ella, se sentía "feliz y libre, sin que nadie me maltrate, ni me reproche".

Hoy en día, Diana no tiene ningún proyecto de vida. Hace un año sus padres viajaron al extranjero y la dejaron encargada con su abuela, junto con su hermanastro. Ella solo deja que el tiempo pase y espera pasivamente a ver qué pasa más adelante. Irresponsablemente cree que de repente se le ocurre algo qué hacer con su vida. Se siente muy sola, se refugia en el alcohol durante las ocasiones en que le permiten salir de su domicilio.

\section{Caso 4}

María tiene 16 años de edad. Reside en el distrito de Miraflores y es estudiante del quinto año de secundaria de un prestigioso colegio particular de Lima. Sus padres son separados. Es una destacada deportista. Su padre reside en el extranjero y únicamente se limita a remitirle suculentas propinas todas las quincenas. En el último año bajó mucho su rendimiento académico, se tornó irresponsable, sin conciencia de su situación. Su madre pagó para que la aprueben el año académico. Se creía más que sus condiscípulas porque pensaba que poseía mejores cosas que ellas. Comenzó a mofarse de cualquier persona que no tuviera el mismo confort que ella. Cree que es muy feliz con los objetos materiales 
que le compran sus padres. Para ella solo existe don dinero y los que no lo tienen en las cantidades que ella recibe son unos "muertos de hambre". Así es de presumida y fatua.

\section{Caso 5}

Michael tiene 17 años de edad. Reside en el distrito de San Miguel y estudia el quinto de secundaria en un acreditado colegio particular del Callao. Cuando inició sus estudios de secundaria comenzó a obtener excelentes calificaciones y era el primero en su clase. Mas cuando cursaba tercero de secundaria, sus padres se separaron por infidelidad materna. Ya en el cuarto año empezó a creerse superior a los demás. Llevaba al colegio equipos de tecnología de punta que aún no había en el país y de los cuales se vanagloriaba. De manera fanfarrona decía que sus compañeros de estudios eran pobres diablos porque no tenían lo que él poseía. También alardeaba que tenía las mejores amistades de Lima y que entrenaba en el mejor club de fútbol del país. Manifestaba que no asistía a las reuniones sociales del Callao porque eran para gente de bajo nivel. Sus padres nunca concurrieron a las actuaciones que se efectuaban en su colegio por el Día del Padre, el Día de la Madre, Fiestas Patrias, etc. Él se excusaba afirmando que sus padres no eran haraganes para ir a sentarse a ver las actuaciones tontas que se realizaban en el colegio. Así, Michael se mostraba aparentemente muy fuerte, simulaba que nunca sufría y que no le faltaba nada. Sin embargo, cuando veía llegar a los padres de sus compañeros al colegio, él se avergonzaba y discretamente se apartaba de sus condiscípulos.

Él solamente sabía llegar todos los días a su colegio a presumir con cada cosa novedosa que traía. Preconizaba que su padre se los traía del extranjero o que él en sus vacaciones iba a conocer diferentes países. Decía sentirse feliz así. Y que sus compañeros eran unos tontos al permitir que sus padres los vayan a ver al colegio, que eso era una humillación, una ofensa.

\section{Caso 6}

Ingrid tiene 19 años de edad, reside en una de las zonas rojas del Callao. Cuando era niña su madre la abandonó en la casa de una tía en Huaraz porque creía que ahí su hija iba a estar mejor atendida y con mayores comodidades. Su madre, de vez en cuando iba a visitarla. En una de esas visitas, Ingrid se lanzó del segundo piso de la casa de su tía, motivo por el cual su madre la trajo a Lima. En adelante, Ingrid se comportó de una manera muy agresiva, fue creciendo con mucho rencor a su madre, abuela y todas las personas que, según ella, la odiaban. Cuando cumplió 17 años conoció a su actual esposo quien le infería muchos maltratos. Ella, todo lo que sentía lo escribía en un cuaderno, maldiciendo su malhadada situación. A la vez, escribía de su amor a un hombre imaginario que no conocía, que se quería embarazar de él a como dé lugar y que si soportaba tantos maltratos era por su hija. Sin embargo, cuando su esposo regresaba a casa y le encaraba que sus amigos le habían comentado que la veían con otro hombre, ella le respondía: "si quieres, golpéame la barriga, te lo juro por nuestro hijo". Así paso el tiempo acumulando y ocultando todo el rencor que sentía por su pareja y su madre hasta que un día su esposo se fue a libar licor. Entonces, ella estalló e hizo un escándalo mayúsculo en casa de sus suegros. Intentó lanzarse desde la azotea, mas logró escaparse 
y cuando la cogieron le encontraron un cuchillo, el cual tenía fuertemente sujetado. Era de madrugada y gritaba en forma desaforada que se quería matar, que odiaba a su madre y nadie la pudo calmar.

Actualmente tiene doble comportamiento. Aparenta llevarse en paz con sus suegros, pero en su casa es otra persona. Maltrata verbalmente a su madre y abuela. No ha recibido ninguna ayuda psiquiátrica. En la vida solamente quiere salir del paso. Cree demostrar a su marido que lo ama practicándose tatuajes en su cuerpo. Es una persona sin sentido de existencia, vive a costas de sus suegros en cuya casa hay muchas comodidades. Ella no tiene la menor intención de ayudar a su cónyuge, ni ayudarse a sí misma. Cuando le reprochan su manera de ser rápidamente retruca diciendo: "son unos exagerados". Se rodea de amigas amorales e irrespetuosas. Su mejor amiga es una adicta.

\section{Caso 7}

Claudia es una adolescente de 18 años, reside en el Callao. Su padre falleció cuando ella tenía 3 años de edad y se crió únicamente con su madre. Cuando fue creciendo convenció a su madre para ingresar al mundo del modelaje, entonces empezó a llevar una doble vida. Salía sola, le daban permiso hasta muy tarde, comenzó a salir con hombres mucho mayores que ella. En el grupo amical era otra persona: desequilibrada, bebía licor en exceso, salía a fiestas con un grupo numeroso de varones y retornaba a su casa muy tarde.

Por el contrario, en su casa era una persona completamente responsable y obediente con su madre. Con su familia fingía mucho; simulaba ser una persona madura que sabía lo que hacia, que se controlaba cuando libaba licor, que quería estudiar una carrera y ser una profesional de éxito. Mas con sus amigas hablaba de otra manera, decía: "¿para qué estudiar? Mejor me consigo un viejo con plata y que él me mantenga. Luego lo dejo y me quedo con la herencia".

Claudia es una chica que solo vive el momento y nada más. Su madre se dedica al trabajo y se ocupa únicamente de lo material, de tener muy buenas amistades y conservarlas.

\section{Caso 8}

Valeria tiene 16 años y reside en el Callao, estudia en un colegio nacional del Callao. Desde los 14 años de edad tiene relaciones sexuales con diferentes parejas. Se justifica manifestando: "Dios dice que nos amemos, así que yo amo a todos los hombres". Vive con su padrastro y su madre; ninguno de ellos la maltrata, pero los dos trabajan y permanentemente son ausentes del hogar. Prácticamente vive sola en su casa donde realiza sus relaciones sexuales. Aún no es consumidora de drogas.

Ella le arrebató el enamorado a su mejor amiga y la explicación que le dio fue así: “¿por qué fuiste tonta? No le diste lo que él te pidió. Ya pues, ahora atente a las consecuencias, porque yo ahora soy su mujer. Y eso no tiene nada de malo".

Valeria cree que es mejor no tener amistades porque según ella estas no valen nada. Por cada enamorado que ha tenido se ha hecho diferentes tatuajes con el nombre de cada uno 
de ellos. Asiste a polladas de barrios muy peligrosos en el Callao y retorna a altas horas de la madrugada a su casa. Es una chica muy sobrevalorada, con soberbia dice: "lo que digan los demás me llega al pelo horquillado que tengo. A mí nadie me da de comer”.

\section{Caso 9}

Andrés es un adolescente de 17 años, reside en el distrito de la Molina. Cuando cumplió 6 años de edad su madre viajó al extranjero en busca de mejores oportunidades y lo dejó encargado con su abuela que reside en el Callao. Su padre era un adicto, por este motivo su madre lo dejó y se fue al exterior con otra pareja.

Andrés fue creciendo y tenía como paradigma a su abuela. Conforme fue creciendo comenzó a juntarse con un grupo de adolescentes de su barrio que pertenecían a las barras bravas y pandillas juveniles. Cada vez que acudía a fiestas con ellos siempre salían peleándose ("guerreadas") con pandillas de otros barrios.

Se refugió por un tiempo en las drogas, las consumía de vez en cuando, pero a su abuela no le faltaba el respeto. Su madre le remitía dinero desde el extranjero, se vestía a la moda, salía todos los fines de semana a fiestas, estaba con diferentes chicas y cuando una de ellas lo engañaba, él lloraba, le echaba toda la culpa a su madre y se refugiaba en las drogas.

Cuando cumplió 15 años de edad conoció a una chica que lo hizo cambiar mucho. Dejó de consumir drogas y se sentía feliz con ella, pero seguía aún un poco rebelde. Al poco tiempo regresó su madre del extranjero y lo encontró muy bien. Sin embargo, él no quiso saber nada de ella. Se portaba muy mal, le contestaba mucho. Después se corrigió y comenzó a tratar de papá a la pareja de su madre porque este señor lo trataba muy bien y le daba buen ejemplo. Su padrastro era capitán de la marina y quería a Andrés como si fuera su hijo.

Su madre lo volvió a dejar con su abuela y se fue al Cusco a supervisar el hotel que tiene ahí. Andrés de nuevo ha regresado a la pandilla y consume drogas de vez en cuando.

\section{Caso 10}

Rony es un adolescente de 17 años, reside en el Cercado de Lima. Ha estudiado en un colegio particular de primera calidad en el Callao. Cuando cumplió 13 años perdió a su hermano mayor, desde entonces sus problemas con las notas se agravaron. En el colegio nadie conoció a su padre. Se sentaba en su carpeta y de ahí nadie lo movía, se ubicaba al fondo del salón de clase y se apartaba de todos sus compañeros. Así pasó toda su primaria y secundaria. Todo este tiempo estuvo en terapia para ver por qué actuaba así, hasta que abandonó el tratamiento. Cuando cursaba el quinto año de secundaria comenzó a presentarse de manera estrafalaria, usaba piercing, peinado extravagante y vestía siempre de negro, con lo cual llamaba la atención.

Por fin se decidió a hablar con unos cuántos condiscípulos, les comentaba que le desagradaba el estudio, que asistía al colegio solo porque su madre lo obligaba y que él prefería estar con sus amigos. Les contaba que tenía un grupo de amigos punk; que todos los viernes se reunían en una casona antigua y desolada, y que ahí hacían de todo cuando a la media 
noche llegaban sus “compañeras que los hacían sentirse relajados y hombres”. Decía que sus amigos eran mayores que él, que ellos fumaban marihuana para relajarse, pero que él nunca la ha probado porque luego salir de eso es difícil. También relataba que iba con sus amigos a carreras de autos ("piques"), que se desvelaba varias noches en la computadora viendo pornografía, y rituales místicos o esotéricos. Refería que para él su madre no existía porque nunca la veía y que mejor era así porque de esta manera no tenía que soportarle sus pachotadas.

Su madre nunca iba al colegio, no obstante que la citaban por la mala conducta de su hijo; aunque más era por sus bajas notas. Rony se siente solo, amargado de la vida, es ateo y solo le interesan los juegos en red, pornografías y asistir todos los viernes a esa casona donde encuentra aparente felicidad y tranquilidad con sus amigos.

\section{Caso 11}

Gina es una adolescente de 18 años, reside en Monterrico. Es una estudiante con muy buenas notas en su colegio. Su padre, médico, nunca quiso tenerla. Una vez su madre se lo enrostró cara a cara a él. Era el primer puesto en su promoción. Cuando cursaba el tercero de secundaria, ella comenzó a salir a fiestas. Como mostraba excelentes notas su madre le daba permiso. Luego empezó a asistir a fiestas muy seguido, su madre no le decía nada, más bien le enseñaba que en esta vida lo que vale es lo material.

Cuando cursaba el cuarto año de secundaria era una adolescente muy "agrandada". Comenzó a salir con diferentes chicos, mentía mucho a su madre, asistía a pijamadas, se aislaba de su familia encerrándose en su dormitorio, escuchaba música a volumen muy alto, se amanecía en el messenger, posaba todas las noches desnuda para el Hi5, le gustaba llamar mucho la atención en el colegio. Posteriormente, ya ella organizaba pijamadas en casa de alguna amiga, así podía amanecerse en las fiestas, tenía muy malas amistades procedentes de barrios muy peligrosos en el Callao y con ellos asistía a polladas, pero no bajaba sus notas para que su madre no la castigara por aquel motivo.

Ya en quinto de secundaria no le daba vergüenza llegar ebria a su casa. Su madre le suministraba dinero para que se haga tatuajes y piercing en su cuerpo, la apoyaba incondicionalmente en todo eso, le traía ropa del extranjero de donde también le remesaban dinero. Hoy estudia en la universidad y su madre cree que por el simple hecho de estar en ella ya no tiene por qué controlarla. Le permite que ella haga lo que mejor le parece y solo se limita a proveerle de dinero en abundancia y a comprarle ropa los fines de semana. $\mathrm{Su}$ madre es una persona amargada y comenta que con ella no se puede hablar.

Gina siempre le cuenta a sus amigas: "mi madre no me quiere. Solo se encarga de llenarme los bolsillos con plata y cuando quiero hablar con ella nunca está. Mejor dicho, está en casa pero no para mí". Gina es muy sensible, durante muchos años esperó que su madre llegara a la actuación del día de la madre en el colegio, pero nunca fue, y no era por trabajo si no que a su madre todo eso le parecía insulso. Por este motivo, ella lloraba mucho ante sus amigas. Una vez, con motivo de un retiro espiritual, presentó una crisis regresiva (berrinche) ante la presencia de todos en el colegio al comprobar que estaban todos los familiares de sus compañeros, pero como siempre su madre no llegó. El director 
llamó a su casa y su madre le contestó así: “dígale a mi hija que venga a casa que no voy porque me duele el pie".

Su madre tampoco le ha dado buen ejemplo porque todos los miércoles no regresaba a casa y solamente le dejaba la comida. Casi nunca almuerzan juntas y cuando esto sucede solo se sientan en la mesa a discutir y pelear. Su madre únicamente le hace reclamos, pero a ella no le importa lo que su madre le diga. Gina piensa que es feliz así, con sus fiestas, amaneciéndose en el messenger, y saliendo con uno y otro chico. Dice: "ahora joven tengo que vivir todo lo que de repente cuando me case no lo haga. Además, hay que aprovechar la juventud que se va volando".

En la actualidad, la relación con su madre es igual de vacía. Gina solo se dedica a llorar al observar que sus amigas tienen una buena comunicación con sus madres.

\section{Caso 12}

Mariana tiene 19 años, reside en el distrito de la Molina y pertenece a una familia de clase alta. Estudió en un colegio privado de primer nivel de Lima, mantiene relaciones sexuales desde los 14 años de edad con diferentes parejas, vive el momento y nada más. A los 15 años salió embarazada y cuando su madre se enteró, le dijo: "bueno, hija, conozco un buen lugar donde abortes a ese feto". Como se sintió apoyada por su madre para el aborto, continuó con sus relaciones sexuales sin cuidado alguno. Asistía a fiestas, conciertos, pijamadas, etc. Después de cada fiesta decía a sus amigas: "bueno ahora me llevarán a un hotel superfashion".

Concurría con sus amigas a carreras clandestinas de autos ("piques") para hacerle barra a sus enamorados, pero ella sentenciaba lo siguiente: "si pierde pues lo dejo, así de fácil, él ya lo sabe”. Viajaba mucho al extranjero, iba y venía, y casi nunca veía a su padre porque él era un hombre de negocios. Actualmente no estudia, su madre la mantiene y cree que después estudiará, que de repente algo se le ocurrirá hacer, pero por ahora tiene que vivir su vida y su juventud.

Mariana varias veces ha salido embarazada y su madre solo sabe decirle: "bueno, hija ya sabes como arreglamos este pequeño problema". Es una adicta a la marihuana; sin embargo, su madre cree que en algún momento ya la dejará porque según ella, "eso es del momento".

\section{Caso 13}

Carlos tiene 19 años y reside en La Punta (Callao). Procede de un hogar donde siempre ha visto mal ejemplo de sus progenitores: su padre engañó a su madre y la abandonó. Su madre salía todos los fines de semana con sus amigas y dejaba a Carlos solo en casa. En su mundo familiar solo se valora lo material. Nunca vio a sus padres en el colegio, a pesar de que los citaban.

A los 16 años inició el consumo de marihuana. En el colegio siempre se refería así de sus padres: "mi padre es un viejo al que le gusta tener a chibolas de amantes, y mi madre es 
una vieja a la que le gusta ponerse jeans apretados para que los viejos le vean el trasero". Repitió el cuarto año de secundaria a pesar de estudiar en uno de los mejores colegios del Callao. No obstante haber reprobado el año escolar y tener muy mala conducta, sus padres no lo cambiaron de colegio. Cuando pasó a quinto año de secundaria embarazó a una chica de su misma edad. Al principio él no quería aceptar que el producto fuera de él, pues comentaba que a su enamorada le gustaba acostarse con cualquiera.

Como sus padres le daban suculentas propinas todas las quincenas y nunca le decían nada por su comportamiento, comenzó a robarle las llaves del auto a su madre para ir a competir en los "piques" con sus amigos. En uno de esos "piques" se accidentó, motivo por el cual faltó al colegio alrededor de un mes. Se negaba a reconocer a su hija, no quería firmarla hasta que lo obligaron judicialmente a que se saque una prueba de ADN que resultó positiva.

Actualmente se está preparando para ingresar a la universidad, pero porque sus amigos lo han persuadido, ya que él no quiere saber nada con los estudios, tanto es así que no sabe ni qué estudiar. Siente que él no es bueno para nada, que solo es bueno para tener a todas las mujeres a sus pies y así es feliz. No consume ninguna droga, pero carece de sentimientos, no sabe lo que es amar.

Su esposa ha viajado al extranjero con su hija y piensa quedarse a residir allá junto a sus padres. A él le da igual, no siente ningún sentimiento hacia su hija, cuyo futuro no le interesa para nada, cree que eso es asunto de su madre. Con displicencia dice: "que ella vea", que ojalá le dé lo mejor a su hija.

\section{Caso 14}

Carolina tiene 17 años y reside en el Callao. Siendo niña perdió a su madre de cáncer al pulmón, su madre era adicta al tabaco. Por esta pérdida su padre se volvió alcohólico. Cuando él retornaba ebrio a casa, impulsado por la cólera golpeaba brutalmente a sus dos hermanas mayores. Así, desfogaba con ellas el dolor de la pérdida de su esposa.

Conforme sus hermanas fueron creciendo, la mayor, a los 18 años, salió embarazada de un joven que mal que bien la ayudó a salir del pozo. Sin embargo, Carolina constató que el esposo maltrataba mucho a su hermana, por este motivo dicha hermana se retiró de la casa paterna a vivir aparte con su cónyuge, quedándose a vivir con el padre, Carolina y su otra hermana mayor. Cuando Carolina se percataba de la ausencia de su padre, salía en busca de él y siempre lo encontraba acostado en un parque completamente alcoholizado. Una vez que su padre estaba sobrio, nuevamente reaparecía su sufrimiento y lo único que hacía era golpear a sus dos hijas y maltratarlas psíquicamente. Cuando la hermana de Carolina cumplió 19 años se aferró a un individuo que era jefe de una barra brava y se fue a vivir con él en un lugar muy peligroso del Callao.

Desde los 15 años de edad Carolina comenzó a salir a polladas con gente muy peligrosa del Callao, se amanecía o no regresaba a su casa después de dos días. Su padre no se inmutaba, ni se molestaba en salir a buscarla. Carolina se sumergió profundamente en el alcohol, su refugio. A los 16 años salió embarazada de un sujeto que tenía 24 años 
de edad. Él estaba requisitoriado por la policía y ya había estado preso más de una vez, pertenecía a una de las bandas más peligrosas del Callao.

Antes que lo capture la policía, Carolina le informó que estaba embarazada de él, pero él no lo aceptó, se negó a reconocer a su hijo y no lo firmó. La hermana del padre de su hija de vez en cuando la visita y le lleva algunos pañales. Ahora ya no se ve a Carolina por la calle. Sus conocidos comentan que está con depresión y que ha intentado suicidarse.

\section{Caso 15}

Mónica tiene 20 años y reside en La Perla, Callao. Su padre falleció cuando ella tenía un año de edad, tiene un hermano mellizo, además, una hermana mayor de 26 años y un hermano menor de 10 años que es del último compromiso de su madre.

Mónica tiene una madre muy sobreprotectora. Conforme fueron creciendo los hijos, su madre no los dejaba salir a ningún lado, ni a jugar con sus amiguitos. Su madre siempre fue una persona sumamente fría y distante con sus hijos a quienes solamente pretendía manipular e internalizarles en la mente ideas absurdas, como por ejemplo; "si ustedes salen a la calle van a caer en el pecado, van a querer drogarse, porque ahí afuera la gente es mala, les tiene envidia". Todos ellos crecieron con esas ideas en la cabeza hasta que su hermana mayor decidió rebelarse y empezar a salir a la calle. Llevó a su madre a tratamiento psicoterapéutico y recién su madre pudo entrar en razón. Progresivamente, ellos empezaron a hacer su vida normal, pero para ellos nunca existió la navidad, su madre no quería saber nada de navidad, ni de año nuevo, los encerraba en su casa.

Su hermana, la mayor a la edad de 18 años, salió embarazada de un hombre de su barrio. Cuando su madre se enteró de tal hecho obligó a su hija a que abortara. Tanto la amenazó que su hija tuvo que acceder. Los tres hermanos fueron creciendo y empezaron a darse cuenta que su madre era una persona enferma y que era adicta al tabaco.

Su hermana mayor, al año siguiente, volvió a salir embarazada, mas se negó a informar a su madre de su estado, pero la madre de todas maneras se llegó a dar cuenta puesto que la observaba rara.

Su madre esperó un mes y la dopó, de manera subprepticia le puso diazepam en la comida. Una vez dormida la llevó para que le hagan el aborto, cuando ella despertó ya estaba en su casa, pero sentía mucho dolor en el cuerpo, sus hermanos únicamente le explicaron que la habían llevado a que le practiquen un chequeo. Su madre hizo abortar a su hija tres veces; sea dopándola o forzándola a que lo haga. Le decía "ese hijo maldito nunca debería de nacer porque es el demonio". La hermana no soportó más la situación y se marchó de su casa.

Su madre decidió mudarse a la av. La Marina. Por entonces, ya había conocido a un señor casado y con familia. La señora decidió embarazarse de este señor solo para chantajearlo y que así él no la abandone.

Cuando ellos ya se instalaron en La Marina, los mellizos habían cumplido 17 años de edad, Mónica empezó a salir con un joven de su mismo barrio, mantuvo relaciones sexuales 
con él y al poco tiempo se fue a vivir a la casa de él. No le dio explicaciones a su madre y se marchó, sólo le dijo que se iba a vivir a la casa de una amiga suya porque ya no la soportaba más.

Mientras transcurría todo ese tiempo, su madre maldecía al padre de su hijo menor, deseándole hasta la muerte. El mellizo de Mónica también empezó a independizarse y en ese tiempo él cayó en las drogas. Su mellizo es una persona inmadura, piensa en mujeres y en estar todo el tiempo en fiestas. Trabaja solo para vestirse y drogarse.

Mónica, durante el tiempo que estuvo viviendo en la casa de su conviviente, conoció a otro hombre con quien le fue infiel y se fue a vivir en casa de este.

Ahora los mellizos tienen 20 años de edad, cada uno hace su vida en lugares diferentes. De vez en cuando van a visitar a su madre. Uno de ellos está sumergido en las drogas. Mónica solo trabaja para poder sobrevivir y los sueños que un día tuvo ya no los piensa cumplir. Quiere seguir su vida, pero a pesar de eso le sigue sacando la vuelta a su pareja. Estos mellizos decidieron llevar una vida libre, lejos de su madre; una madre que les demostraba muy poco afecto. Su madre vive sola con su hijo menor en una casa muy grande con más de cinco dormitorios y sufre de depresión.

\section{Caso 16}

Claudia y Jorge son mellizos de 18 años y residen en Miraflores. Sus padres son divorciados, vienen de un hogar carente de afecto. Su padre es un profesional de éxito y adicto a la marihuana. Su madre es una señora que siempre salía por las noches y no regresaba hasta el siguiente día, solo se ocupaba de su apariencia física. Ellos son dos mellizos que no conocieron el amor, ni el cariño de sus padres. Estudiaron en un colegio A1 de Lima.

Conforme fueron creciendo su vida se volvió muy oscura, vacía. Cada uno hacía su vida por su lado.

Estos mellizos eran muy inteligentes en las matemáticas, pero cuando cursaban ya el cuarto año de secundaria sus padres los sacaron de aquel colegio y los pusieron en un colegio preuniversitario, mandándolos a vivir con su abuela en el Callao.

Después de esto se volvieron muy rebeldes, Claudia empezó a salir con diferentes chicos y a sumergirse, junto con su hermano, en las drogas. En la actualidad ha recorrido tanto la vida que a los 18 años de edad sabe más que una mujer de 26 años.

Claudia y Jorge actualmente viven con su abuela, pero un día ella se va con su madre y su hermano con su padre o viceversa. Comentan que se aburren de estar con ellos y regresan donde su abuela a esperar que sea fin de semana para irse a campamentos, pijamadas o fiestas.

\section{Caso 17}

Jimmy es un adolescente de 13 años de edad que reside en el distrito de Los Olivos (Lima Norte). Es estudiante del tercer año de secundaria en un colegio estatal, su padre es un abogado que ejerce en una ciudad andina del centro del país y su madre una química farmacéutica que no ejerce su profesión. El padre es de carácter violento y castrador; de 
niño castigó brutalmente a Jimmy por lo cual este lo odia. Durante la niñez de sus hijos, ambos padres permanecían muchas horas del día fuera del hogar. Actualmente se encuentran separados. Jimmy es el tercero de cuatro hermanos. Su hermano mayor, Robert quien le lleva 3 años de edad, es ciberadicto, motivo por el cual se encuentra actualmente internado en un servicio de adicciones, fue él quién indujo a Jimmy a dedicarse a ver televisión hasta altas horas de la noche, y mientras el resto de la familia dormía se dedicaban a jugar "haciendo el amor", cuando ambos tenían aproximadamente entre 6 y 9 años de edad.

Actualmente, su comportamiento es demandante, inquisidor, desobediente muchas veces necio, su mayor deseo es ser un "chico normal" y para ello debería salir a jugar videojuegos como lo hacen todos sus amigos, además tener permiso para reunirse con sus amigos tres horas de lunes a jueves y cuatro horas de viernes a domingo, sin tener que dar cuenta a donde irá.

Detesta que se le recoja del colegio, para él es lo peor, es una vergüenza, pues no es ningún bebé. Cuando ve a su madre se hace el que no la ha visto y a veces realmente no la ve, entonces se dirige con toda libertad junto a sus amigos a jugar pinbol o playstation, si su hermana lo intercepta para pedirle que vaya a casa le contenta "lárgate, no me jo...".

Como estudiante es indiferente, le da lo mismo pasar los cursos a las justas, por el contrario sacar buenas notas es ser sumiso ("hincha”) y eso, según él, "apesta”, "qué palta"; igual que asistir al colegio correctamente uniformado. Es mejor asistir con la camisa afuera y con polos de color debajo de la casaca del buzo.

Es exigente para vestir, le gusta la ropa de moda, pantalones sueltos, zapatillas de marca y pretende usar el cabello con gel erizado, como no se le permite, se moja constantemente el cabello, aspira a tener celular con cámara para tomarse fotos y MP3 para escuchar música. Así mismo, anhela tener una bicicleta moderna GT para poder salir con alguien, sueña con ponerse aretes, ya que, según él, eso es normal en la juventud de ahora, y a él se le vería muy bien, pues su tez es blanca. Sentimentalmente es indiferente, duro con las necesidades de los demás, si hace algo, pide gratificación económica, cree que sabe mucho, critica duramente a su hermano Roberto por haberse dejado absorber en el juego, ya que "por culpa de ese maldito" no puede hacer algo que es propio de su edad, jugar y salir libremente.

\section{REFERENCIAS BIBLIOGRÁFICAS}

1. Cyrulnik, Boris (2005). Bajo el signo del vínculo. Una historia natural del apego. Barcelona: Editorial Gedisa S. A.

2. Cyrulnik, Boris (2007). De cuerpo y alma. Neuronas y afectos: la conquista del bienestar. Barcelona: Editorial Gedisa S. A.

3. De Rotterdam, Erasmo. (2004). Elogio de la locura. Madrid: Herder Editorial, S. L. Biblioteca de Filosofía. Mestas ediciones.

4. Frankl, Víktor E. (1994). La voluntad de sentido. Conferencias escogidas sobre logoterapia. Barcelona: Editorial Herder. 
5. Frankl, Víktor E. (2000). En el principio era el sentido. Reflexiones en torno al ser humano. Barcelona: Ediciones Paidós Ibérica, S. A.

6. Frankl, Víktor E. (2001). Ante el vacío existencial. Hacia una humanización de la psicoterapia. Barcelona: Editorial Herder. Barcelona.

7. Frankl, Víktor E. (2003). El hombre en busca de sentido. Barcelona: Herder Editorial, S. L.

8. Frankl, Víktor E. (2003). Psicoterapia y existencialismo. Escritos selectos sobre logoterapia. Barcelona: Herder Editorial, S. L.

9. Fromm, Erich (2007). La vida auténtica. Barcelona: Paidós Nueva Biblioteca Erich Fromm.

10. Luna, J. A. (1999). Logoterapia. Un enfoque humanista existencial. Santa Fe de Bogotá: San Pablo.

11. Nizama, Martín (2003). Guía para el manejo familiar de las adicciones. Lima: Fondo Editorial Universidad Alas Peruanas.

12. Nizama, Martín (2009). Tratamiento familiar holístico de las adicciones. Modelo familiar. Lima: Centro de Producción Editorial e Imprenta de la Universidad Nacional Mayor de San Marcos.

13. Russell, Bertrand (2003). La conquista de la felicidad. En Diario El País, 55-65, 227-233. 